\title{
Flow diverter devices in the treatment of posterior communicating artery aneurysms: mid-term clinical and radiological outcomes
}

\author{
Mahmoud Moubark ${ }^{1 *}$, Abd El-Kareem Abd Allah ${ }^{1}$, Hosam Yosef ${ }^{1}$, Mohamed Abdel-Tawab $^{1}$, Parschakis Panos ${ }^{2}$ \\ and Mostafa Othman'
}

\begin{abstract}
Background: In the last decade, flow diverter (FD) devices are one of the widely used endovascular methods in the treatment of intracranial aneurysms. As the frequency of its use is increasing progressively, we thought that studies concerned with the use of FD at specific locations are helpful to clarify the efficacy and safety of FD as a treatment option in cerebral aneurysms. We represent our experiences in the treatment of posterior communicating artery (PCOM) aneurysms by FD devices aiming to assess its angiographic efficacy (complete aneurysm occlusion) and its related complications. This is a retrospective study of 47 patients harboring 47 PCOM aneurysms treated with Pipeline Embolization Device (PED). Acutely ruptured and non-saccular aneurysms were excluded from the study. Short- and mid-term radiological and clinical outcomes were analyzed.

Results: Procedure-related complications were observed in five patients (two ischemic events, two transient ischemic attacks (TIA), and one ipsilateral distal hemorrhage) with no procedure-related mortality. Complete aneurysm occlusion was encountered in $87.2 \%$. In multivariable analysis, large-sized aneurysm and incorporated vessels were an independent predictor of non-occlusion ( $P=0.026$ and $P=0.035$ respectively). A favorable clinical outcome (modified Rankin Scale, 0-2) was observed in 45/47 patients (95.7\%); the incidence of postoperative complications was an independent predictor of unfavorable clinical outcomes $(P=0.048)$.
\end{abstract}

Conclusion: PED stent provides a high occlusion rate in the treatment of PCOM aneurysms with good posttreatment clinical outcomes.

Keywords: Cerebral Aneurysm, Complications, Endovascular, Flow diverter

\section{Background}

PCOM aneurysms is considered as the second common site of the brain aneurysms. It accounts for about $25 \%$ of overall brain aneurysms and about $50 \%$ of internal carotid artery aneurysms [1]. A wide range of anatomical variations exits with PCOM aneurysms, and it directly

\footnotetext{
* Correspondence: mahmoud.abdelzaher@med.au.edu.eg

'Department of Diagnostic and Interventional Radiology, Assiut University, Assiut, Egypt

Full list of author information is available at the end of the article
}

affects the treatment strategy and choices of appropriate line of treatment [2].

Treatment options of PCOM aneurysm include surgical clipping and endovascular techniques; surgical treatment is preferable in large aneurysm especially when it is causing mass effect on the oculomotor nerve, aneurysms with unfavorable fundus, and those associated with fetal PCOM artery origin [3, 4].

Endovascular treatment with detachable coils has been advocated as an alternative treatment of aneurysms with accepted efficacy and safety [5-7]. The proximal location

\section{Springer Open}

() The Author(s). 2020 Open Access This article is licensed under a Creative Commons Attribution 4.0 International License, which permits use, sharing, adaptation, distribution and reproduction in any medium or format, as long as you give appropriate credit to the original author(s) and the source, provide a link to the Creative Commons licence, and indicate if changes were made. The images or other third party material in this article are included in the article's Creative Commons licence, unless indicated otherwise in a credit line to the material. If material is not included in the article's Creative Commons licence and your intended use is not permitted by statutory regulation or exceeds the permitted use, you will need to obtain permission directly from the copyright holder. To view a copy of this licence, visit http://creativecommons.org/licenses/by/4.0/. 
of PCOM aneurysms, as well as a good visualization of aneurysmal neck and parent artery, makes coiling procedures of PCOM aneurysms more easily in comparison to other sites of the intracranial aneurysm, but a high rate of recanalization after endovascular coiling is still the most drawback of PCOM aneurysm coiling [2].

Flow diverter devices are promising new generation of brain stents with low porosity $[8,9]$ that have a different mode of actions, in contrast to endovascular coiling which depends on packing of the aneurysmal sac. Aneurysm occlusion via flow diversion (FD) explained by two mechanisms: (1) the effect of FD in inhibition of the blood in and outflow through the aneurysm and (2) reinforcement and repair of the parent artery wall using the stent mesh as the scaffold for an intimal generation (scaffolding effect) [10]. The interruption of the aneurysm inflow jet strikingly reduces shear stresses on the aneurysm fundus with progressive thrombosis of the aneurysm over time; shrinkage of the aneurysm occurred during healing after inflammatory response with reconstructing the parent artery lumen while preservingperforators and side branches [11].

Despite the large number of reports that evaluate FD in the treatment of intracranial aneurysms, the clinical and radiological outcomes of PCOM aneurysms treated by FD which consider as one of the frequent sites of brain aneurysms not evaluated in-depth in previous studies, we concern in this study the post-treatment complications and occlusion rate of PCOM aneurysms treated by Pipeline flow diverter stent on mid-term follow-up.

\section{Methods}

This is a retrospective analysis of 47 patients harboring 47 aneurysms arising from the PCOM artery and treated by Pipeline flow diverter stent between March 2014 and September 2016 in two tertiary institutes. Declaration of Good Clinical Practice was approved by the Ethics Review Board of the institutes, and signed informed consent was obtained from all patients before the procedure.

Dual antiplatelet therapy is needed after PED placement which limited its use to highly selective cases of ruptured intracranial aneurysm. So, in our study, patients with recent ruptured aneurysms $\leq 30$ days and non-saccular aneurysms were excluded from the study.

\section{Pre and post-procedure medications}

All patients were kept on dual antiplatelet therapy for 5 days before the procedure. All received $75 \mathrm{mg} /$ day clopidogrel and $81 \mathrm{mg} /$ day aspirin; the post-procedural antiplatelet regimen consisted of clopidogrel continued for 6 months following the treatment, and aspirin continued for 1 year.

\section{Procedure}

All procedures were done under general anesthesia via an $8 \mathrm{~F}$ right femoral introducer. A long stiff introducer $6 \mathrm{~F}$ was advanced to the level of the internal carotid artery (ICA); then, 3D rotational angiography obtained to select the work projection.

Pipeline-type flow diversion stent (ev3-Covidien, Irvine, CA, USA) deployed in co-axial navigation of a MARKSMAN microcatheter distal to the aneurysmal neck at least $10 \mathrm{~mm}$ and then pushing the stent to the tip of the delivery wire. The system is then aligned with the aneurysm under fluoroscopy, PED stent deployed, and the microcatheter is withdrawn. Closure of the femoral puncture point with a Femoseal system was done after checking the patency of the common femoral artery.

\section{Follow-up}

Angiographic follow-up by digital subtraction angiography (DSA) or magnetic resonance angiography (MRA) was scheduled at 180 days, 1 year, and 2 years after treatment. As DSA image is the golden standard to assess the aneurysm occlusion, we scheduled it two times during the first 24 months while MRI/MRA was done for patients with neurological symptoms during this period, then patients were followed annually by MRI/MRA. DSA and MRI/MRA were independently reviewed by two authors using O'Kelly-Marotta (OKM) [12] to evaluate the rate of aneurysm occlusion.

Clinical follow-up was done with modified Rankin Scale (mRS), and clinically significant procedure-related complications were reported.

\section{Statistical analysis}

Categorical variables were expressed as number (n) and percentage, and continuous variables were expressed as median \pm quartiles and/or means \pm standard deviation.The univariate conditional (matched) analysis was used to test covariates predictive of the following dependent variables: angiographic occlusion and clinical outcomes (modified Rankin Scale, 0-2 versus 3-6). Interaction and confounding were assessed through stratification and relevant expansion covariates. Factors predictive in univariate analysis $(P<0.20)$ were entered as multivariate conditional logistic regression analysis. $P$ values of $\leq 0.05$ were considered statistically significant. IBM SPSS Version 23.0 (IBM Corp., Armonk, New York, USA) was used for data administration and statistical calculations.

\section{Results}

\section{Baseline characteristics}

Patient's ages ranged from 32 to 73 years; the median was 51 years (IQR 44-64); 40 patients (85.1\%) were 
females; and seven patients (14.9\%) were males. The mean size of the target aneurysms was $10.05 \mathrm{~mm}$ (SD \pm $5.62)$; two aneurysms (4.3\%) were giant $\geq 25 \mathrm{~mm}, 17$ aneurysms $(36.2 \%)$ were large-sized $\geq 10 \mathrm{~mm}$, and 28 aneurysms (59.6\%) were small-sized with 17 aneurysms $(36.2 \%)$ that had unfavorable dome-to-neck ratio $(\leq 1.5)$.

The presentation of the aneurysms was variable: ten (21.3\%) manifested by third cranial nerve (CN III) compression symptoms, nine $(19.1 \%)$ represented with headache, $12(25.5 \%)$ aneurysms incidentally discovered, and 16 aneurysms (34\%) were recurrent after previous treatment (Table 1).

\section{Aneurysm treatment}

Deployment of FD success in 46/47 (97.8\%) patients, one PED failed to release during the procedure resulting in immediate ipsilateral ICA occlusion (Figs. 1 and 2). A single PED was inserted in the treatment of 37 (78.4\%) aneurysms, two stents were used in the treatment of eight aneurysms (17\%), and three stents were used in the treatment of two aneurysms (4.3\%); the mean PED used per procedure was 1.25. Balloon angioplasty was acquired in three procedures (one FD with malposition required to use to post-deployment dilation and in two procedures to obtain optimal stent expansion after multiple PED stent deployed in a telescopic manner). Four (10.6\%) aneurysms were treated with adjunctive coils in addition to PED stent(s) to completely secure the aneurysm neck and sac (one giant aneurysm treated with two PED and coiling, one large aneurysm with incorporated vessels treated with two PED and coiling, and two

Table 1 Aneurysm characterization

\begin{tabular}{ll}
\hline Aneurysm characteristics & $n(\%)$ \\
\hline Aneurysm presentation & $12(25.5)$ \\
Incidental & $10(21.3)$ \\
Nerve palsy & $9(19.1)$ \\
Headache & $16(34)$ \\
Recurrent & \\
Aneurysm size & $28(59.6)$ \\
$\quad$ Small size < 10 mm & $17(36.2)$ \\
Large size 10-24 mm & $2(4.3)$ \\
$\quad$ Giant $\geq 25$ mm & \\
Dome-to-neck ratio & $30(63.8)$ \\
$\quad>1.5$ (favorable dome-to-neck ratio) & $17(36.2)$ \\
$\quad \leq 1.5$ (unfavorable dome-to-neck ratio) & $5(10.6)$ \\
Same segment another aneurysm & $2(4.3)$ \\
Thrombosed aneurysm & $1(2.1)$ \\
Fetal origin PCom & $9(19.1)$ \\
Incorporated vessels &
\end{tabular}

PCOM posterior communicating artery wide neck aneurysm treated with single PED and coiling).

\section{Procedure-related complications}

Procedure-related complications occurred in five (10.6\%) patients (two ischemic events, two TIA, and one ipsilateral distal hemorrhage) and resulted in persistent neurological morbidity in two $(4.2 \%)$ patients. No procedurerelated mortality was encountered.

Hemorrhagic complications occurred in one patient who was an active smoker and hypertensive harboring a large sized 18.8-mm aneurysm treated by single PED stent and developed ipsilateral distal hemorrhage $<24 \mathrm{~h}$ after the procedure, and patient complained from decrease visual acuity in terms of homonymous superior quadrantanopia with last mRS 2 .

Ischemic complications occurred in two patients. One patient with large sized aneurysm $(19.5 \mathrm{~mm})$ was treated with two PED stents which occluded 6 months after primary treatment with an ipsilateral infraction; the patient developed contralateral hemiplegia with last mRS 3. Another patient suffered from ischemic complications secondary to an intra-procedure event in terms of a failure of proper release of PED stent in the treatment of a small-sized $(9 \mathrm{~mm})$ aneurysm with ipsilateral ICA occlusion and immediate post-operative hemiplegia with last mRS 3.

Transient ischemic attacks occurred in two patients. One patient harboring giant aneurysm treated by two PED stents with adjuvant coiling developed transient contralateral hemiplegia 1 month after treatment which completely resolved with last $\mathrm{mRS} 0$. Another patient with large sized aneurysm $13.8 \mathrm{~mm}$ treated by single PED stent patient developed transient receptive aphasia $<24 \mathrm{~h}$ after treatment which resolved spontaneously with last mRS 0 .

\section{Clinical outcome}

All patients underwent clinical assessment during the follow-up period with the median follow-up time of 30 months (IQR 24-34). A favorable outcome (modified Rankin Scale $\leq 2$ ) was observed in 45 patients $(95.7 \%)$. The 2 patients who had a poor clinical outcome had experienced procedure-related complications, mRS was stationary in $36(76.6 \%)$ patients, improvement in mRS observed in nine $(19.1 \%)$ patients, and deterioration in mRS occurred in two (4.2\%) patients; change in mRS overtime is listed in Table 2.

The following factors were tested for as predictors of outcome: age, sex, aneurysm size, wide neck, incorporated vessels, aneurysmal thrombosis, unfavorable dometo-neck ratio, the fetal origin of PCOM, previous treatment, and postoperative complications. In univariable analysis, the only factor predicting the poor clinical 


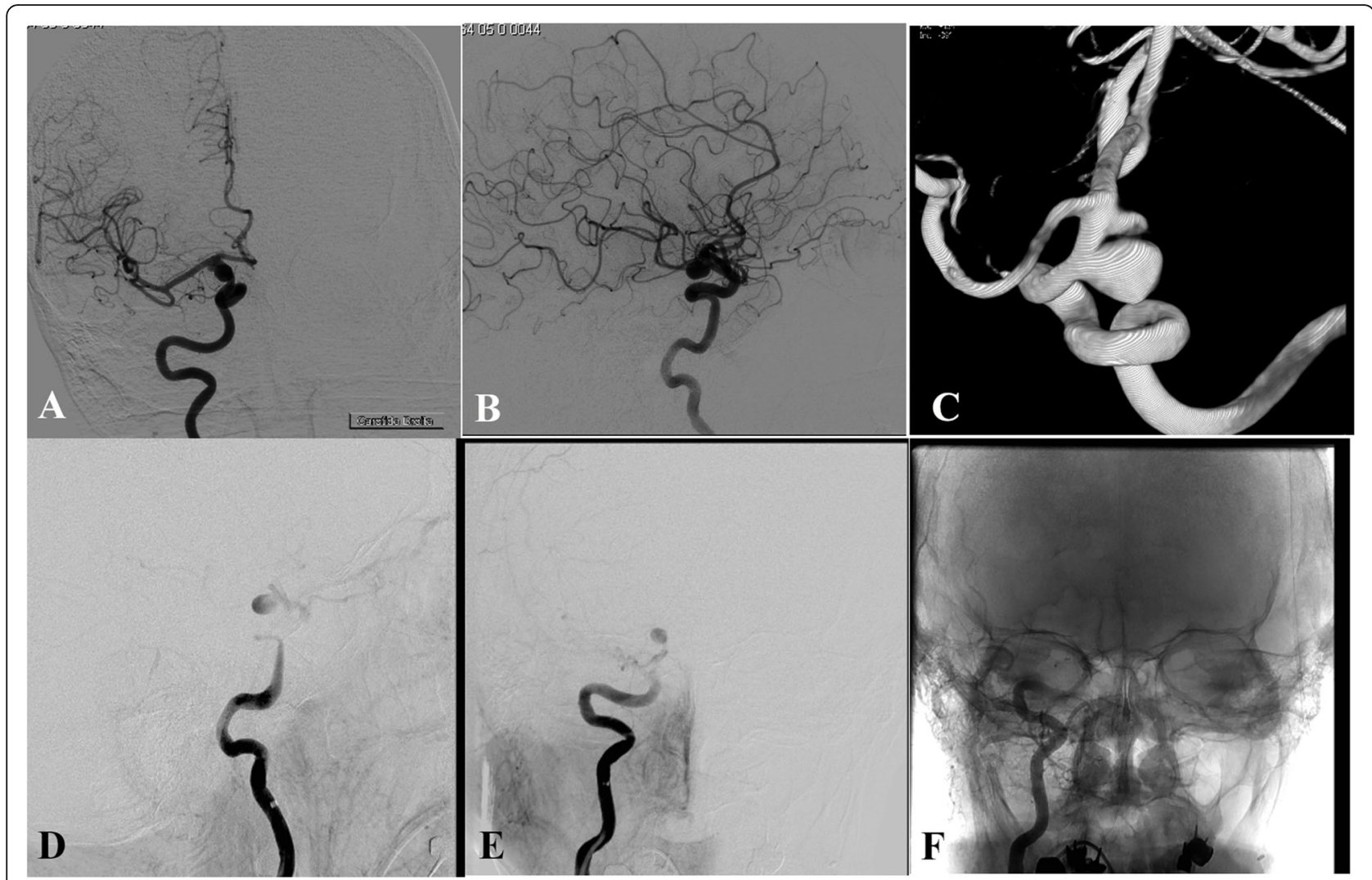

Fig. 1 a-c DSA of 54- years old patient with incidentally discovered small-sized right PCOM artery aneurysm, $\mathbf{d}$ failure of release PED stent $3.75 \times$ $18 \mathrm{~mm}$, with occlusion of ipsilateral ICA (e) and noted revascularization of the right ACOM artery and to a lesser extent of the right MCA (f)

outcome (modified Rankin Scale, > 2) was postoperative complications (odds ratio, 6.428; $95 \%$ confidence interval, $1.02-37.68 ; P<0.048$ ) (Table 3 ).

\section{Angiographic outcome}

All patients underwent angiographic DSA follow-up at least at one time according to our schedule at 180 days, 1 year, and 2 years (Table 4), excluding the patient with failed PED release. Thirty-eight patients (82.6\%) underwent DSA twice, and 8 patients have DSA once during the first 2 years, while MRI/MRA was done for $11 \mathrm{pa-}$ tients during this period and then scheduled annually for all patients. We used the O'Kelly-Marotta scale to assess the occlusion of the treated aneurysm. At 24 months, all patients underwent DSA, with the exclusion of aneurysm with failed PED deployment; the overall complete occlusion rate was reported in 41 aneurysms (89.1\%) (Fig. 3). Six aneurysms failed to achieve complete occlusion (one giant, one large-sized aneurysm with incorporated vessels, three aneurysms with incorporated vessels, and one aneurysm had incorporated vessels with fetal origin PCOM).

Retreatment was necessary for two un-occluded aneurysms; both were large-sized aneurysms $(19 \mathrm{~mm}$ and 16 $\mathrm{mm})$ that were retreated at 6th and 12th months after the primary treatment respectively.

The following factors were tested for as predictors of occlusion: age, sex, aneurysm size, wide neck, incorporated vessels, aneurysmal thrombosis, unfavorable dome-toneck ratio, the fetal origin of PCOM, previous treatment, and post-operative complications. In univariable analysis, factors predicting non-occlusion were incorporated vessels $(P<0.08)$ and large size aneurysm $(P=0.01)$. In multivariable analysis, both large size aneurysm (odds ratio, 5.205; 95\% confidence interval, 1.215-22.297; $P<0.026$ ) and incorporated vessels (odds ratio, 3.205; 95\% confidence interval, $3.215-28.297 ; P<0.035)$ were statistically significantly independent predictor of non-occlusion (Table 5).

\section{Discussion}

The article studies as regards PCOM treatment by flow diverter almost concern with patency of PCOM after PED deployment $[13,14]$ or discuss failure/low occlusion of PCOM aneurysms associated with a fetal origin posterior cerebral artery after flow diverter [15-18]; few articles discuss the clinical and radiological outcome of fetal and non-fatal PCOM artery aneurysms [6]. Our study describes the clinical and radiological outcomes of 


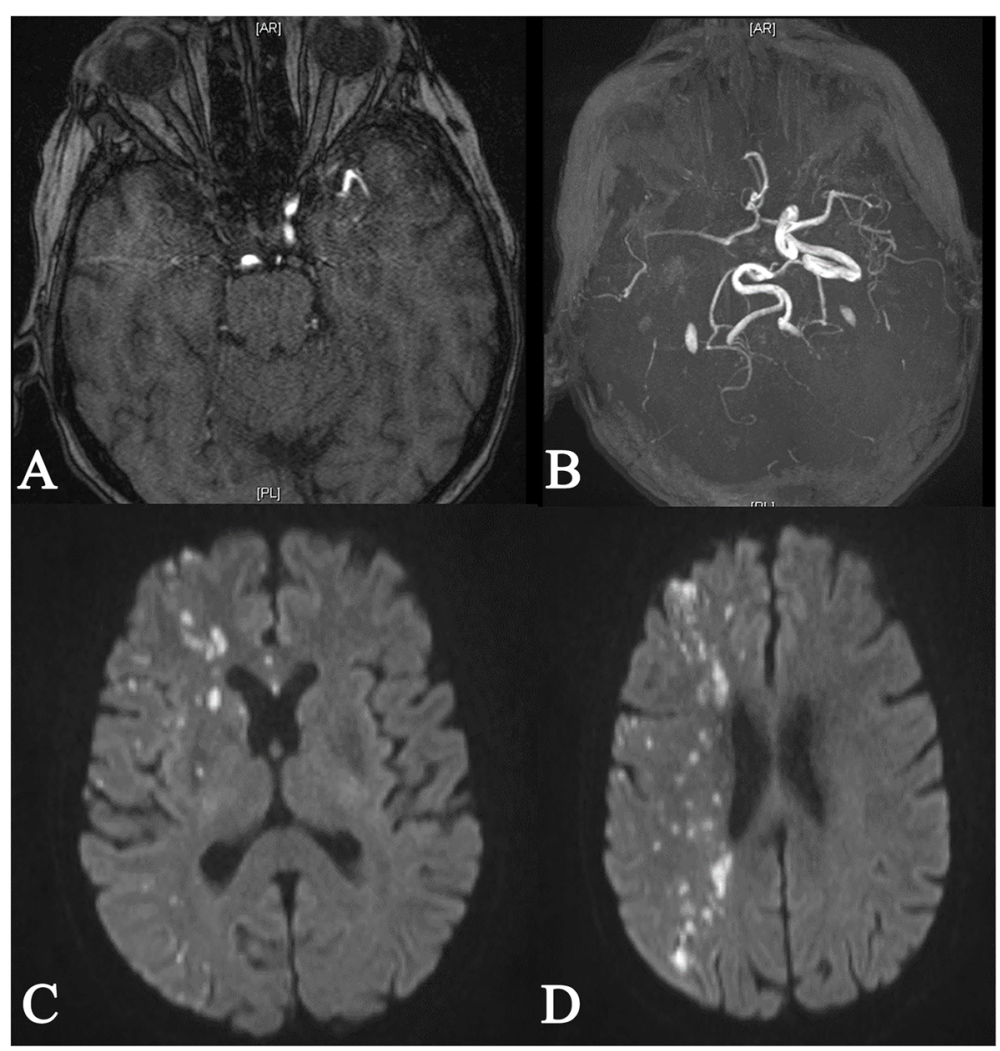

Fig. 2 a-d: MRI of the same patient demonstrates occlusion of right ICA with subsequent multiple ischemic infarcts along right MCA territory

PCOM aneurysms treated with flow diverter stent (PED type) in two tertiary institutes. This study has data regarding the anatomical variants and clinical presentation that give better ideas to assess the post-procedure complications and clinical and radiographic outcomes of PCOM aneurysms treated by PED stent.

Endovascular coiling remained the treatment of choice of most of the intracranial aneurysms, but it has low rates of occlusion in complex and large-sized aneurysms [19]. FD offered an alternate treatment option for those complex and large/giant aneurysms [20].

Table 2 modified Ranking Score (mRS) over time

\begin{tabular}{llllll}
\hline mRS* $^{*}$ & Admission & Discharge & 1 year & 2 years & Last mRS \\
\hline 0 & $32(68.1 \%)$ & $32(68.1 \%)$ & $36(76.6 \%)$ & $37(78.7 \%)$ & $38(80.8 \%)$ \\
1 & $10(21.3 \%)$ & $9(19.1 \%)$ & $6(12.7 \%)$ & $5(10.6 \%)$ & $4(8.5 \%)$ \\
2 & $3(6.4 \%)$ & $3(6.4 \%)$ & $1(2.1 \%)$ & $1(2.1 \%)$ & $1(2.1 \%)$ \\
3 & $2(4.3 \%)$ & $2(4.3 \%)$ & $3(6.4 \%)$ & $3(6.4 \%)$ & $4(8.5 \%)$ \\
4 & 0 & $1(2.1 \%)$ & $1(2.1 \%)$ & $1(2.1 \%)$ & 0 \\
5 & 0 & 0 & 0 & 0 & 0 \\
6 & 0 & 0 & 0 & 0 & 0 \\
\hline
\end{tabular}

Data expressed in number(percentage)

${ }^{*} m R S$ modified Ranking Score, 0 no symptoms, 1 no significant disability, 2 slight disability, 3 moderate disability, 4 moderately severe disability, 5 severe disability, and 6 dead
In our series, procedure-related complications occurred in five patients (two ischemic, two TIA, and one ipsilateral distal hemorrhage) with persisting major neurological deficits in two patients (4.2\%) and no procedure-related mortality.

The post-procedure complications after PCOM treatment in Roy et al. [18] study occurred only in one patient who suffered from seizure with no major

Table 3 Univariate logistic regression of predictors of clinical outcomes

\begin{tabular}{llll}
\hline & $P$ value & OR & Cl 95\% \\
\hline Age & 0.854 & 1.574 & $0.302-5.213$ \\
Sex & 0.999 & - & - \\
Large size & 0.094 & 0.161 & $0.019-1.363$ \\
Wide neck & 0.873 & 1.125 & $0.264-4.795$ \\
Incorporated vessels & 0.481 & 1.846 & $0.335-10.165$ \\
Intraluminal thrombus & 0.999 & - & - \\
Unfavorable dome-to-neck ratio & 0.844 & 0.857 & $0.185-3977$ \\
PCOM fetal origin & 0.450 & 1.214 & $0.525-11.075$ \\
Previous treatment & 0.485 & 0.464 & $0.054-4.003$ \\
Post-operative complications & $\mathbf{0 . 0 4 8 *}$ & 6.428 & $1.02-37.68$ \\
\hline
\end{tabular}

$\mathrm{Cl}$ confidence interval, $O R$ odds ratio, $P C O M$ posterior communicating artery *Statistically significant difference $(P \leq 0.05)$ 
Table 4 Angiographic (DSA) follow-up over time

\begin{tabular}{llll}
\hline OKM scale & 180 days, $n(\%)$ & 12 months, $n(\%)$ & 24 months, $n(\%)$ \\
\hline A & $1(5.5)$ & $2(5.5)$ & - \\
B & $4(22.2)$ & $4(11.1)$ & $3(8.8)$ \\
C & $3(16.6)$ & $9(25)$ & $6(17.6)$ \\
D & $11(61.1)$ & $22(61.1)$ & $26(74.5)$ \\
Missed & 28 & 10 & 12 \\
\hline
\end{tabular}

OKM O'Kelly-Marotta scale for the angiographic outcome, $A$ total filling (> $95 \%), B$ subtotal filling (5-95\%), $C$ entry remnant $(<5 \%), D$ no filling $(0 \%)$

neurological complications. Daou et al.'s [14] study has no ischemic or hemorrhagic complications, and the same is reported by Kühn et al. [6].

As a meta-analysis including 3125 patients, the overall complications $17.0 \%$ with mortality rate $2.8 \%$, and the neurological morbidity $4.5 \%$ [21], the authors concluded that the use of FD stents in aneurysms treatment yielded satisfactory results with regard to the complications and the mortality rate. In Trivelato et al.'s [22] study, the major strokes or mortality rate was $3.45 \%$. Likewise, in Adeeb et al.'s [23] study, the symptomatic thromboembolic complications were $12 \%$ and symptomatic hemorrhagic complications $8 \%$ with no mortality; they concluded that the incidence of complications after PED is greater in giant and large aneurysms compared to smaller sized aneurysms.
Distal intraparenchymal hemorrhage is the most dreaded complication of flow diversion. In our study, only one active smoker, hypertensive patient with large PCOM aneurysm who suffered from ipsilateral parenchymal hemorrhage required surgical evacuation and complained from contralateral homonymous superior quadrantanopia, because of the effect of hemorrhage on Meyer's loop in the temporal lobe.

Distal parenchymal hemorrhage more in anterior circulation aneurysms was treated by FD [24]; the exact mechanism of bleeding is not clearly understood and may be explained by alteration of the parent artery morphology and decrease in the local compliance of the vascular segment affecting the aneurysm hemodynamics [25]; the presence of risk factors as smoking and hypertension with endovascular microvascular damage as well as the use of antiplatelet therapy increases the bleeding risks.

Delayed aneurysm rupture after FD is one of the serious complications with disastrous consequences and is more common in symptomatic and large/giant aneurysms [26]. In the current study, no delayed rupture occurred, it may be attributed to small sample size, and most of the treated aneurysms in our series were smallsized (59.6\%).

In contrast to hemorrhage after FD, ischemic complications are more common in treated posterior circulation aneurysms [27] and also more common in large and

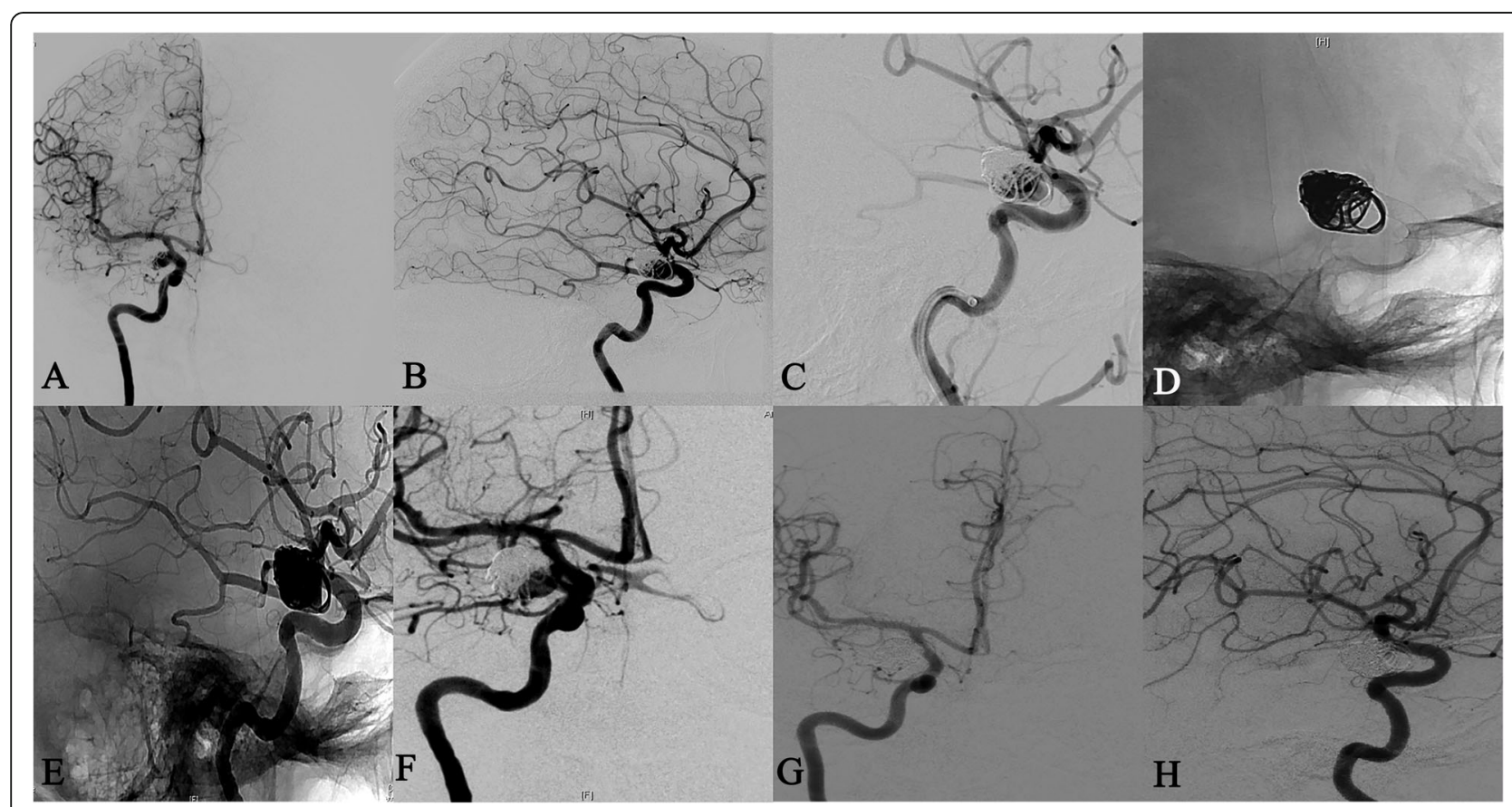

Fig. 3 a-c DSA of 43-years old patient, showing recanalized right PCOM aneurysm 1 year after coiling. $\mathbf{d}$ Insertion of single PED stent $4 \times 16 \mathrm{~mm}$. e, f Angiography immediately after PED deployment. $\mathbf{g}$, $\mathbf{h}$ One-year follow-up revealed complete occlusion of the aneurysm 
Table 5 Univariate and multivariate logistic regression of predictors of angiographic outcomes

\begin{tabular}{|c|c|c|c|c|c|c|}
\hline & \multicolumn{3}{|c|}{ Univariate } & \multicolumn{3}{|c|}{ Multivariate model } \\
\hline & $P$ value & OR & Cl $95 \%$ & $P$ value & OR & $\mathrm{Cl} 95 \%$ \\
\hline Age & 0.763 & 0.776 & $0.148-4.060$ & - & - & - \\
\hline Sex & 0.858 & 0.869 & $0.135-4.012$ & & & \\
\hline Large size & $0.007^{*}$ & 11.429 & $1.933-67.568$ & $0.026^{*}$ & 5.205 & $1.215-22.297$ \\
\hline Wide neck & 0.338 & 2.350 & $0.409-13.509$ & - & - & - \\
\hline Incorporated vessels & $0.036^{*}$ & 6.250 & $1.128-34.639$ & $0.035^{*}$ & 3.205 & $3.215-28.297$ \\
\hline Intraluminal thrombus & 0.318 & 0.305 & $0.030-3.131$ & - & - & - \\
\hline Unfavorable dome-to-neck ratio & 0.118 & 0.267 & $0.051-1.401$ & & & \\
\hline Fetal origin of PCOM & 0.2580 & 0.2869 & $0.1035-1.012$ & - & - & - \\
\hline Previous treatment & 0.117 & 0.261 & $0.049-1.403$ & - & - & - \\
\hline Postoperative complications & 0.057 & 0.192 & $0.035-1.049$ & - & - & - \\
\hline
\end{tabular}

$\mathrm{Cl}$ confidence interval, $\mathrm{OR}$ odds ratio, $P C O M$ posterior communicating artery

*Statistically significant difference $(P \leq 0.05)$

giant aneurysms [26, 28]. In our study, two patients suffered from thromboembolic events on the 1st day and the 6th month after FD procedures respectively. The first is due to improper deployment of PED and resulting in ipsilateral ICA occlusion. The second patient harboring large aneurysm was treated by two PED stents and developed intra-stent stenosis 6 months after treatment; it attributed to interruption of anti-platelet therapy, and also the use of multiple stents with intraprocedure microvascular injuries changes the hemodynamic and promotes the incidence of ischemic complications [29].

Complete aneurysm occlusion in the present study was achieved in $41 / 46$ aneurysms $89.1 \%$ of treated aneurysms and re-treatment required in two aneurysms. The relatively high rate of complete aneurysm occlusion in our study is in line with the findings of previous series especially those concerned with PCOM aneurysm after PED stent: in Roy et al.'s [18] study, complete or nearcomplete occlusion was achieved in $85.4 \%$, Daou et al. [14] reported $86.7 \%$ complete or near-complete obliteration at 6-month follow-up, Kühn et al. [6] observed complete or near-complete occlusion in $91.5 \%$ at 3 to 9 months, and Brinjikji et al. [13] realized 81.8\% complete or near-complete occlusion at the last follow-up.

Progressive aneurysm occlusion over time was observed in many studies as in Dornbos et al. [30] and Saatci et al.'s [9] studies; in our series complete occlusion progress from $61.1 \%$ at $6-12$ months to $74.5 \%$ at 24 months, the exact mechanism of progressive occlusion over time may be explained by progressive intra-saccular thrombus formation over time and shrinkage of the aneurysm with the inflammatory process reaction.

Failure of complete occlusion in our study was observed in six aneurysms; incorporated vessels and large size aneurysm were statistically significant factors associated with low occlusion rate, and among those with incorporated vessels, one aneurysm has a fetal origin of the PCOM artery which was identified as a predictor for low occlusion, but in our study, its non-statistical significant as a low number of cases with fetal origin was included in our series.

The presence of incorporated artery increases difficulties in endovascular treatment of the aneurysm; flow diverters provided a solution for those aneurysms [31]; we identified that incorporated vessels from the aneurysmal sac/neck is an independent predictor of incomplete aneurysm occlusion, the same announced in many studies [14, 22, 32-35]. It is explained by pressure gradient kept by incorporated branch toward the aneurysm that reduced the flow diversion effect of the stent and in PCOM aneurysm theoretical explanation by retrograde filling of the sac via the posterior circulation resulting in residual aneurysm filling after treatment [22].

A lager aneurysmal size is associated with low occlusion rate the same realized in many studies $[9,27$, $32,34,36,37]$. Fetal origin PCOM artery almost always associated with failure of aneurysm occlusion [14-17]; it explains by high demand flow in largecaliber fetal PCOM artery keep the flow to it and disrupt the flow diversion effect.

\section{Limitations}

The limitations of our study are related to its retrospective design and absence of randomization and also the relatively small series of patients and shorter follow-up time. Despite these limitations, our study provides the first study concerned only with PCOM aneurysms treated by FD devices. 


\section{Conclusions}

In this study, we assess the PED stent as a flow diverter device in terms of its efficacy and clinical outcomes in patients with unruptured saccular PCOM aneurysms. We found that the FD provides high aneurysm occlusion rates with lower retreatment rates. The morbidity and unfavorable mid-term clinical outcomes were not negligible when using FD devices. Caution and proper management of antiplatelet therapy are required when using FD devices to treat PCOM aneurysms.

\section{Recommendations}

Further studies on the underlying mechanism of the adverse events with a large number of patients are required.

\begin{abstract}
Abbreviations
ACA: Anterior cerebral artery; ACOM: Anterior communicating artery; FD: Flow diverter; PCOM: Posterior communicating artery; PED: Pipeline Embolization Device; TIA: Transient ischemic attack; mRS: Modified Rankin Scale; ICA: Internal carotid artery; DSA: Digital subtraction angiography; MRI: Magnetic resonance imaging; MRA: Magnetic resonance angiography; OKM: O'Kelly-Marotta; CN: Cranial nerve
\end{abstract}

\section{Acknowledgements}

The authors thank all the study participants for their patience and support.

\section{Authors' contributions}

A. A., M. O., and H.Y suggested and developed the research idea and reviewed the literature. M. M., P. P. H. Y., and M. A. were responsible for the data collection and analysis, perform statistical analysis, write and revise the manuscript, prepare cases and perform required measurements, and prepare figures and tables. M. M. and P.P. were responsible for reporting the clinical and angiographic outcomes of the cases during the follow-up period. All authors have a major contribution in preparing and editing the manuscript. All authors read and approved the final manuscript.

\section{Funding}

No fund

\section{Availability of data and materials}

The data that support the findings of this study are available from Radiology department-Assiut University, but there are restrictions that apply to the availability of data, which used under license for this study and so were not publicly available. Data were available from authors upon request with permission of the head of the Radiology department- Assiut University.

\section{Ethics approval and consent to participate}

This study had approval from two tertiary institutes in Egypt (Assiut University, Faculty of Medicine Research Ethics Committee) and in France (Pierre Wertheimer Hospital, Lyon). All patients who participated in this study signed informed written consent for participation.

\section{Consent for publication}

A verbal consent to publish was obtained.

\section{Competing interests}

Authors declare that they had no competing interests.

\section{Author details}

'Department of Diagnostic and Interventional Radiology, Assiut University, Assiut, Egypt. ${ }^{2}$ Department of Radiology, Hôpital Neurologique, Lyon, France.
Received: 10 June 2019 Accepted: 26 June 2020

Published online: 07 July 2020

\section{References}

1. Zheng F, Dong Y, Xia P, Mpotsaris A, Stavrinou P, Brinker G et al (2017) Is clipping better than coiling in the treatment of patients with oculomotor nerve palsies induced by posterior communicating artery aneurysms? A systematic review and meta-analysis. Clin Neurol Neurosurg 153:20-26

2. Gunnal SA, Farooqui MS, Wabale RN (2018) Anatomical variability of the posterior communicating artery. Asian J Neurosurg 13(2):363

3. Fukami S, Akimoto J, Fukuhara H, Kohno M (2018) Microvascular Decompression for Oculomotor Nerve Palsy Due to Compression by Infundibular Dilatation of Posterior Communicating Artery. World Neurosurg 119:142-145

4. Khan S, Smith T, Zomorodi A, McDonagh D, Agrawal A, Alexander M et al (2013) Effect of surgical clipping versus endovascular coiling on recovery from oculomotor nerve palsy in patients with posterior communicating artery aneurysms: a retrospective comparative study and meta-analysis. Asian J Neurosurg 8(3):117

5. Hall S, Sadek A, Dando A, Grose A, Dimitrov B, Millar J et al (2017) The resolution of oculomotor nerve palsy caused by unruptured posterior communicating artery aneurysms: a cohort study and narrative review. World Neurosurg 107:581-587

6. Kühn A, Dabus G, Kan P, Wakhloo A, Puri A (2018) Flow-diverter stents for endovascular management of non-fetal posterior communicating artery aneurysms - analysis on aneurysm occlusion, vessel patency, and patient outcome. Interv Neuroradiol 24(4):363-374

7. Griessenauer C, Goren O, Dalal S, Schirmer C (2018) Pipeline Embolization Device with Shield Technology for intracranial aneurysms: an initial U.S. experience. World Neurosurg 119:10-14

8. Wong GK, Kwan MC, Ng RY, Simon C, Poon W (2011) Flow diverters for treatment of intracranial aneurysms: current status and ongoing clinical trials. J Clin Neurosci 18(6):737-740

9. Saatci I, Yavuz K, Ozer C, Geyik S, Cekirge H (2012) Treatment of intracranial aneurysms using the pipeline flow-diverter embolization device: a singlecenter experience with long-term follow-up results. Am J Neuroradiol 33(8): $1436-1446$

10. Tateshima S (2017) Basics of the flow diverter: development and principles. J Neuroendovasc Ther 11(3):105-108

11. Yavuz K, Geyik S, Saatci I, Cekirge H (2014) Endovascular treatment of middle cerebral artery aneurysms with flow modification with the use of the pipeline embolization device. Am J Neuroradiol 35(3):529-535

12. O'kelly C, Krings T, Fiorella D, Marotta T (2010) A novel grading scale for the angiographic assessment of intracranial aneurysms treated using flow diverting stents. Interv Neuroradiol 16(2):133-137

13. Brinjikji W, Lanzino G, Cloft HJ, Kallmes DF (2014) Patency of the posterior communicating artery after flow diversion treatment of internal carotid artery aneurysms. Clin Neurol Neurosurg 120:84-88

14. Daou B, Valle-Giler EP, Chalouhi N, Starke RM, Tjoumakaris S, Hasan D et al (2017) Patency of the posterior communicating artery following treatment with the Pipeline Embolization Device. J Neurosurg 126(2):564-569

15. Tsang ACO, Fung AMY, Tsang FCP, Leung GKK, Lee R, Lui WM (2015) Failure of flow diverter treatment of intracranial aneurysms related to the fetal-type posterior communicating artery. Neurointervention 10(2):60

16. Zanaty M, Chalouhi N, Starke R, Jabbour P, Ryken K, Bulsara K et al (2016) Failure of the Pipeline Embolization Device in posterior communicating artery aneurysms associated with a fetal posterior cerebral artery. Case Rep Vasc Med 2016:1-4

17. Kan P, Duckworth E, Puri A, Velat G, Wakhloo A (2016) Treatment failure of fetal posterior communicating artery aneurysms with the pipeline embolization device. J Neurointervent Surg 8(9):945-948

18. Roy AK, Howard BM, Haussen DC, Osbun JW, Halani SH, Skukalek SL et al (2018) Reduced efficacy of the pipeline embolization device in the treatment of posterior communicating region aneurysms with fetal posterior cerebral artery configuration. Neurosurgery 82(5):695-700

19. Murakami T, Nishida T, Asai K, Kadono Y, Nakamura H, Fujinaka T et al (2019) Long-term results and follow-up examinations after endovascular embolization for unruptured cerebral aneurysms. Am J Neuroradiol 40(7):1191-1196

20. Slater L-A, Soufan C, Holt M, Chong W (2015) Effect of flow diversion with silk on aneurysm size: a single-center experience. Interv Neuroradiol 21(1): $12-18$ 
21. Zhou G, Su M, Yin Y-L, Li M-H (2017) Complications associated with the use of flow-diverting devices for cerebral aneurysms: a systematic review and meta-analysis. Neurosurg Focus 42(6):E17

22. Trivelato FP, Rezende MTS, Ulhôa AC, de Castro-Afonso LH, Nakiri GS, Abud DG (2018) Occlusion rates of intracranial aneurysms treated with the Pipeline embolization device: the role of branches arising from the sac. J Neurosurg 1(aop):1-7

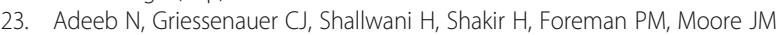
et al (2017) Pipeline embolization device in treatment of 50 unruptured large and giant aneurysms. World Neurosurg 105:232-237

24. Meckel S, McAuliffe W, Fiorella D, Taschner CA, Phatouros C, Phillips TJ et al (2013) Endovascular treatment of complex aneurysms at the vertebrobasilar junction with flow-diverting stents: initial experience. Neurosurgery 73(3): 386-394

25. Burrows AM, Cloft H, Kallmes DF, Lanzino G (2015) Periprocedural and midterm technical and clinical events after flow diversion for intracranial aneurysms. J Neurointervent Surg 7(9):646-651

26. Kulcsár Z, Houdart E, Bonafe A, Parker G, Millar J, Goddard A et al (2011) Intra-aneurysmal thrombosis as a possible cause of delayed aneurysm rupture after flow-diversion treatment. Am J Neuroradiol 32(1):20-25

27. Brinjikji W, Murad MH, Lanzino G, Cloft HJ, Kallmes DF (2013) Endovascular treatment of intracranial aneurysms with flow diverters: a meta-analysis. Stroke 44(2):442-447

28. Briganti F, Leone G, Marseglia M, Mariniello G, Caranci F, Brunetti A et al (2015) Endovascular treatment of cerebral aneurysms using flow-diverter devices: a systematic review. Neuroradiol J 28(4):365-375

29. Nossek E, Chalif DJ, Chakraborty S, Lombardo K, Black KS, Setton A (2015) Concurrent use of the Pipeline Embolization Device and coils for intracranial aneurysms: technique, safety, and efficacy. J Neurosurg 122(4):904-911

30. Dornbos D, Karras CL, Wenger N, Priddy B, Youssef P, Nimjee SM et al (2017) Pipeline embolization device for recurrence of previously treated aneurysms. Neurosurg Focus 42(6):E8

31. Lubicz B, Lefranc F, Levivier M, Dewitte O, Pirotte B, Brotchi I et al (2006) Endovascular treatment of intracranial aneurysms with a branch arising from the sac. Am J Neuroradiol 27(1):142-147

32. Chiu A, Cheung A, Wenderoth J, De Villiers L, Rice H, Phatouros $C$ et al (2015) Long-term follow-up results following elective treatment of unruptured intracranial aneurysms with the pipeline embolization device. Am J Neuroradiol 36(9):1728-1734

33. Kan P, Srinivasan VM, Mbabuike N, Tawk RG, Ban VS, Welch BG et al (2016) Aneurysms with persistent patency after treatment with the Pipeline Embolization Device. J Neurosurg 126(6):1894-1898

34. Moshayedi H, Omofoye OA, Yap E, Oyekunle TO, Sasaki-Adams DM, Solander SY (2017) Factors affecting the obliteration rate of intracranial aneurysms treated with a single Pipeline embolization device. World Neurosurg 104:205-212

35. Shapiro M, Becske T, Nelson PK (2017) Learning from failure: persistence of aneurysms following pipeline embolization. J Neurosurg 126(2):578-585

36. Adeeb N, Moore J, Wirtz M, Griessenauer C, Foreman P, Shallwani H et al (2017) Predictors of incomplete occlusion following Pipeline embolization of intracranial aneurysms: is it less effective in older patients? Am J Neuroradiol 38(12):2295-2300

37. Bender MT, Colby GP, Lin L-M, Jiang B, Westbroek EM, Xu R et al (2018) Predictors of cerebral aneurysm persistence and occlusion after flow diversion: a single-institution series of 445 cases with angiographic followup. J Neurosurg 130(1):259-267

\section{Publisher's Note}

Springer Nature remains neutral with regard to jurisdictional claims in published maps and institutional affiliations.

\section{Submit your manuscript to a SpringerOpen ${ }^{\circ}$ journal and benefit from:}

- Convenient online submission

- Rigorous peer review

- Open access: articles freely available online

- High visibility within the field

- Retaining the copyright to your article

Submit your next manuscript at $\boldsymbol{\nabla}$ springeropen.com 